\title{
FOTOETNOGRAFIA DE UMA CONGADA
}

\author{
Cristiano das Neves Bodart ${ }^{1}$ \\ Rochele Tenório da Silva ${ }^{2}$
}

Esta fotoetnografia foi realizada nas "franjas" da " $106^{\circ}$ Festa a São Benedito", acorrido em 04 de janeiro de 2015, na pequena comunidade de Alto Rio Calçado, no município de Guarapari, estado do Espírito Santo. O evento é marcado pela ritualização de uma das congadas mais antigas realizada anualmente nesse estado. A comunidade que remonta aos anos após abolição da escravatura tem origem quilombola, o que explica os traços afrodescendentes de maior parte dos moradores.

O uso da fotografia em trabalhos etnográficos não almeja apenas esclarecer o saber científico, mas promover condições de melhor compreensão humanística do que o outro tem a dizer para os demais que querem ver, ouvir e sentir (Andrade, 2002). É nesse sentido que este ensaio objetiva propiciar ao leitor condições sensitivas para a compreensão da cultura, no caso específico, da congada da comunidade em questão. Partimos, assim, do pressuposto de que a fotoetnografia pode revelar elementos aparentemente ausentes e não percebidos pelo pesquisador no momento que se passa a cena registrada (Berger, 2007: 6), assim como nos possibilita repensarmos elementos não observados e anotados no campo.

A metodologia adotada considerou as contribuições de Achutti (2004), para quem o trabalho fotoetnográfico deve deixar claro sua finalidade, assim como ter como aporte um planejamento de coleta de imagens e sua organização. Para ele:

Se desde o princípio do trabalho de campo, o pesquisador-fotógrafo não tiver em mente a paginação final [...], o resultado de seu trabalho sofrerá desta falta de planificação, pois uma narrativa visual que pretenda utilizar a fotografia deve ser fruto de um longo processo de construção, a construção de uma descrição visual. As fotografias no resultado final devem formar um todo. Por esta razão, uma obra que utilize a fotografia deverá ser construída com método [...]. Fotografias obtidas de maneira aleatória e desorganizada tornar-se-ão, no melhor dos casos, uma fonte de informação que terminará por encontrar talvez um dia seu lugar em alguma fototeca, mas que não poderão vir a ser uma obra completa, uma narrativa fotoetnográfica" (Achutti, 2004: 3-4).

\footnotetext{
${ }^{1}$ Universidade de São Paulo, Brasil.

${ }^{2}$ Universidade de Vila Velha, Brasil.
} 
Nesse sentido, foram realizadas entrevistas a alguns membros da comunidade e ao mestre da congada, a fim de compreender previamente todos os momentos do rito e seus significados para aquela comunidade. Esse momento foi fundamental para definirmos previamente um planejamento, compondo uma "narração" minimamente linear do evento.

Atestamos que a fotoetnografia proporciona uma sensação de captura da realidade, ao mesmo tempo que nos oferece a certeza de sua impossibilidade (Leal, 2013), uma vez que nos desperta para fragmentos de tempo-espaço de uma realidade complexa.

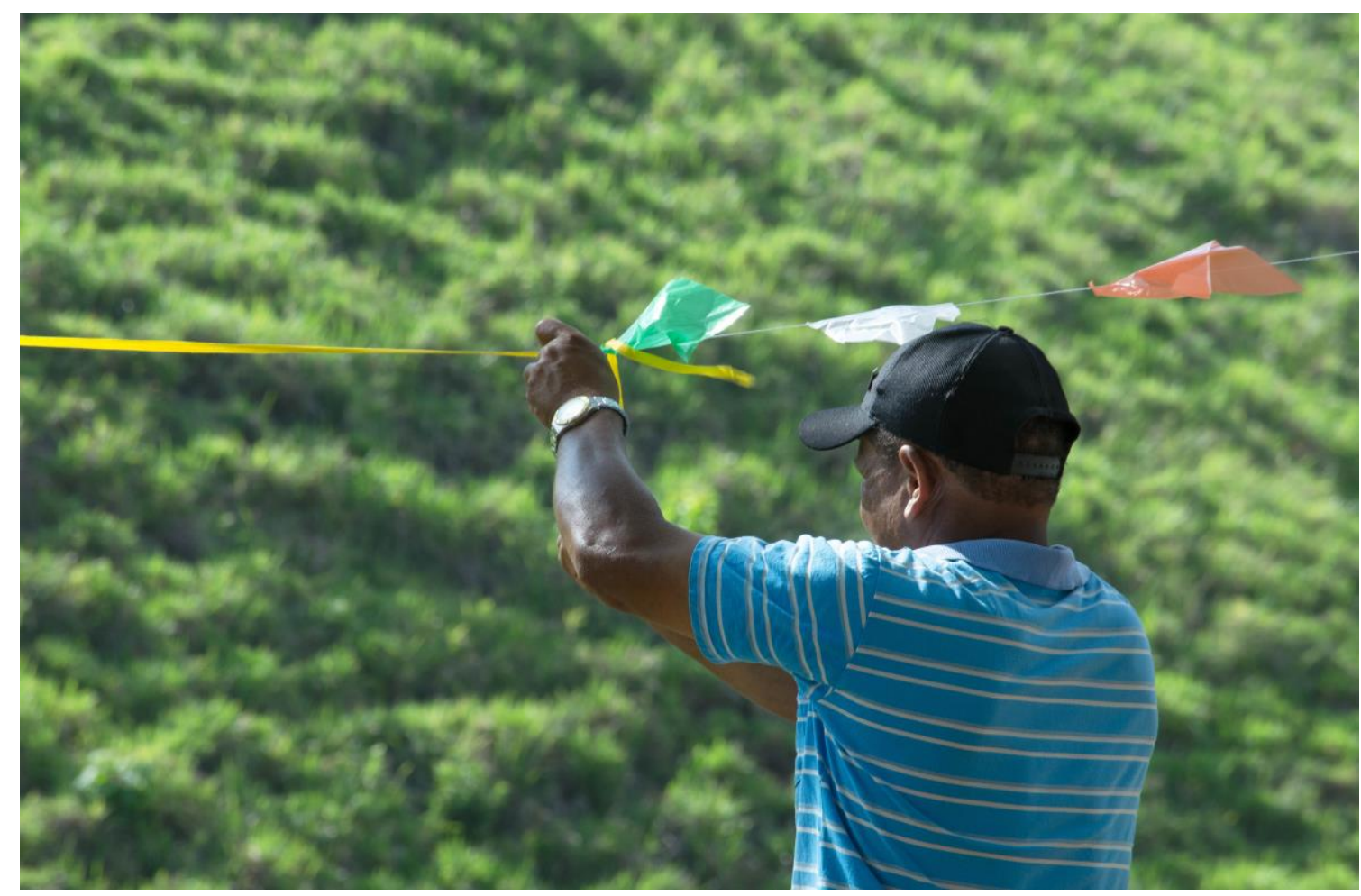

Ornamentação para agradar ao santo. Bandeirinhas, flores e panos coloridos são marcas do rito. Homens e mulheres se envolvem nessa atividade, a qual inicia-se ainda no dia anterior. Foto: Cristiano das Neves Bodart. 


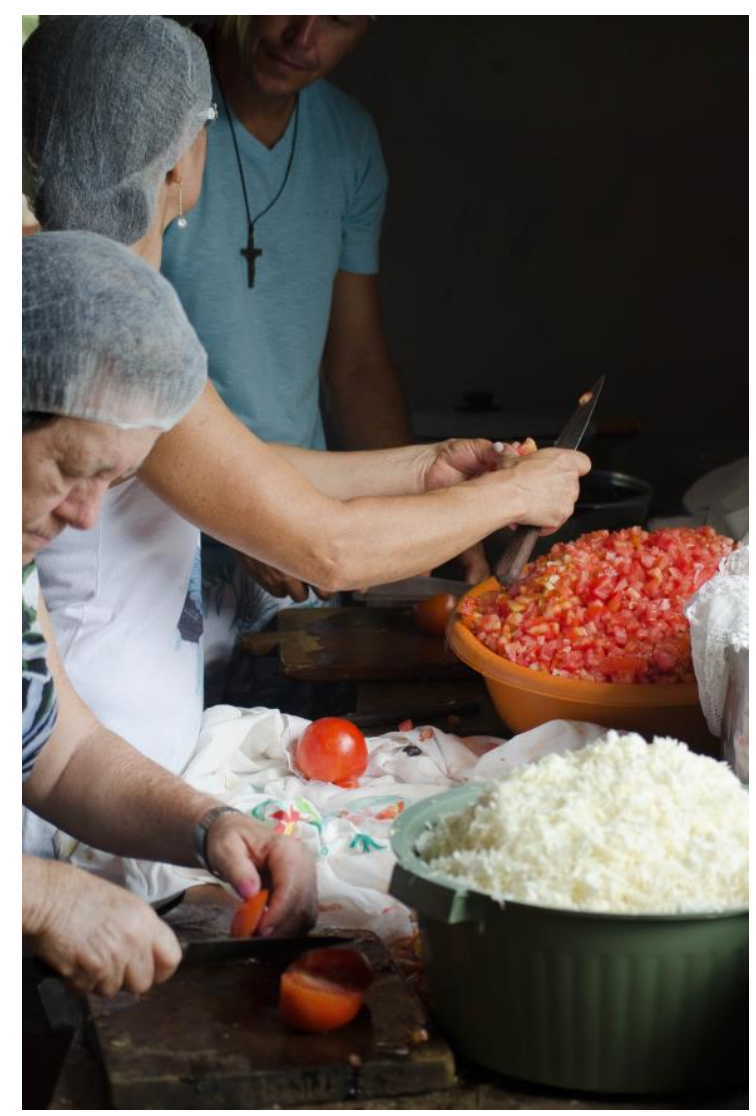

O preparo do alimento para receber os fiéis. Foto: Cristiano das Neves Bodart.

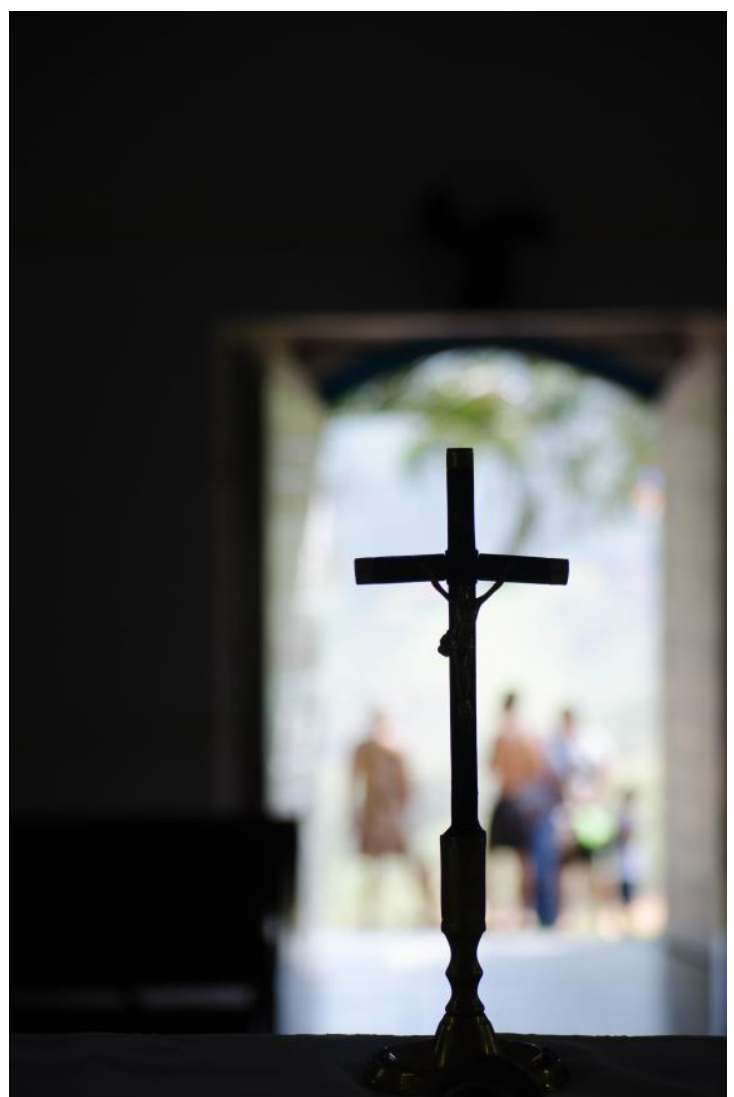

O rito tem início apenas após uma missa a São Benedito. Foto: Cristiano das Neves Bodart.

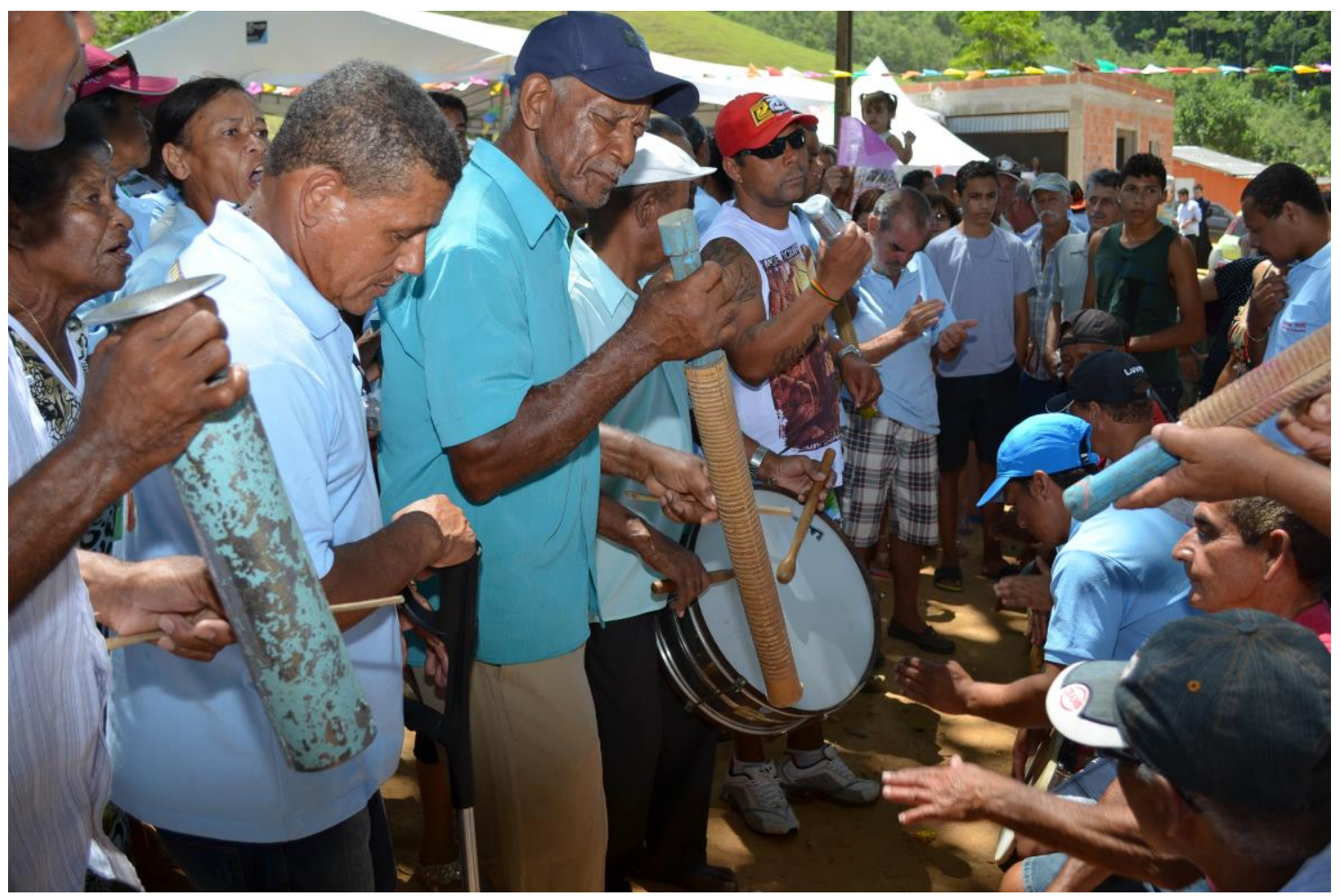

Após a celebração da missa, deu-se início a tradicional congada. Por meio de cantos, tambores, casacas e outros instrumentos típicos, alguns recentemente incluídos, estabelecia-se o ritmo afrodescendente. Foto: Cristiano das Neves Bodart.

Iluminuras, Porto Alegre, v. 17, n. 41, p. 329-339, jan/jun, 2016. 


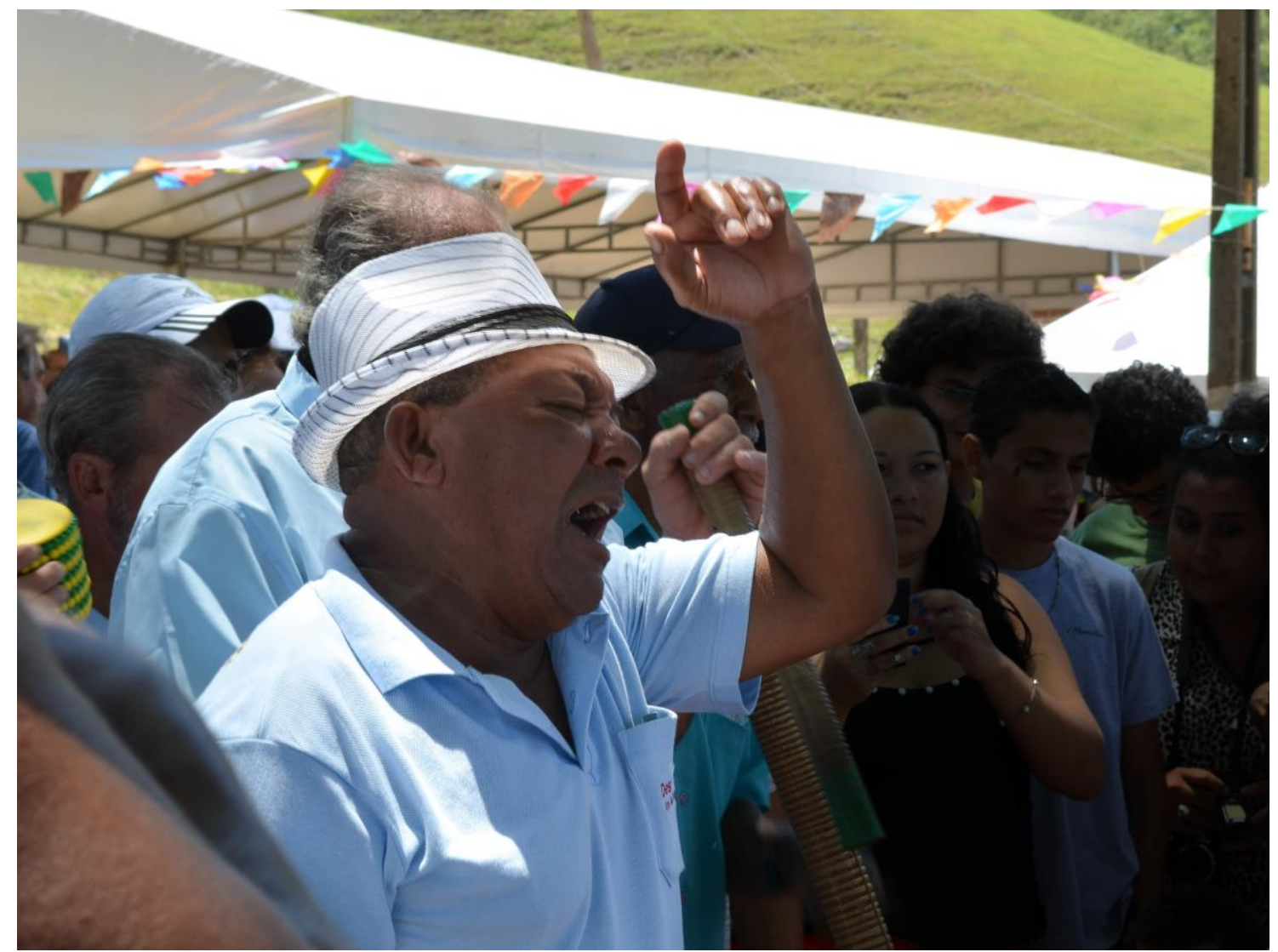

A cantoria é ditada pelo "mestre", o qual, por meio de um apito, dita o início e o término de um canto, o qual pode ser "puxado" por qualquer participante do rito. Foto: Cristiano das Neves Bodart.

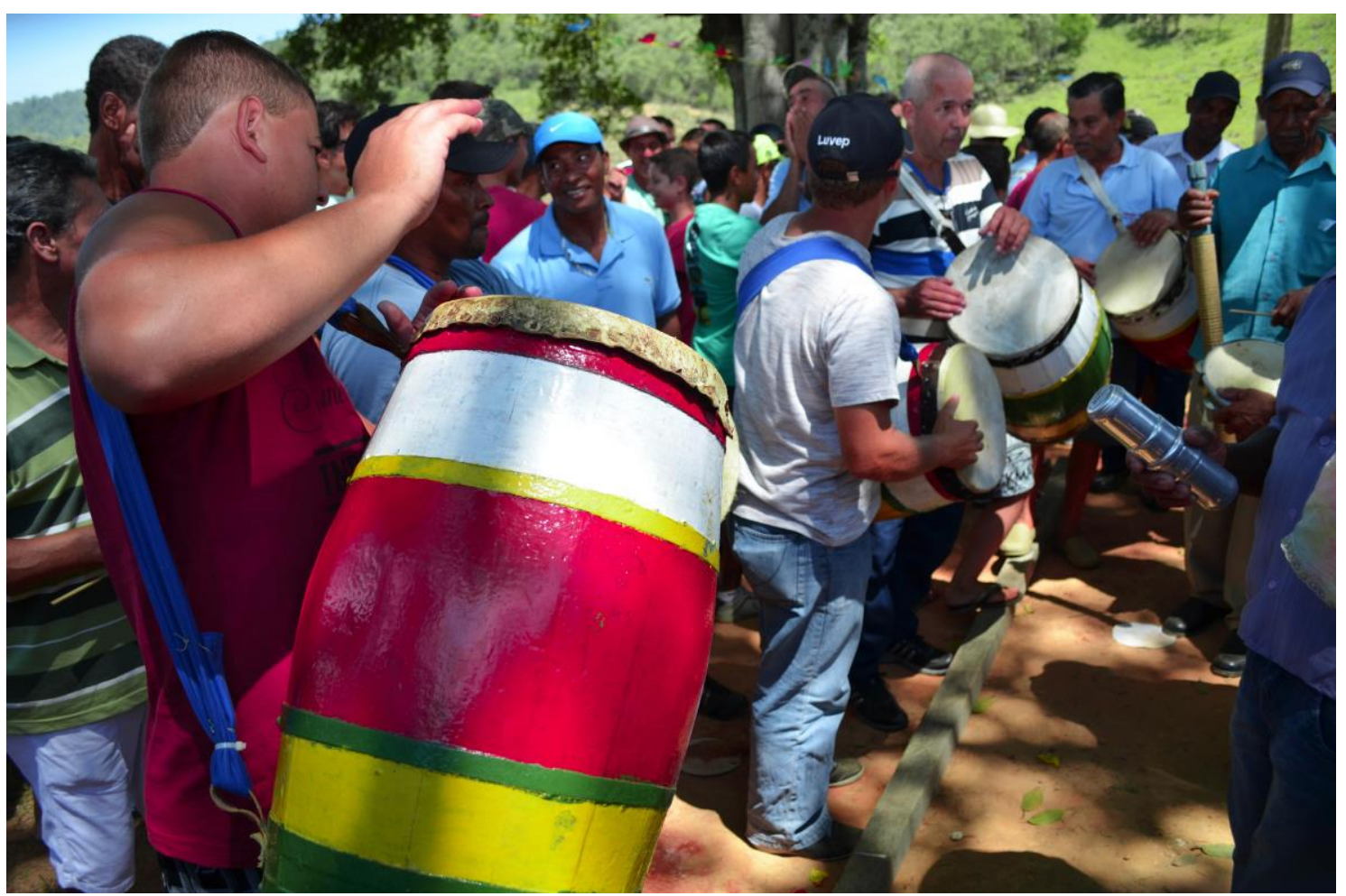

Os tambores: manifestação de alegria, exaltação da história da comunidade e louvor a São Benedito. Foto: Cristiano das Neves Bodart.

Iluminuras, Porto Alegre, v. 17, n. 41, p. 329-339, jan/jun, 2016. 


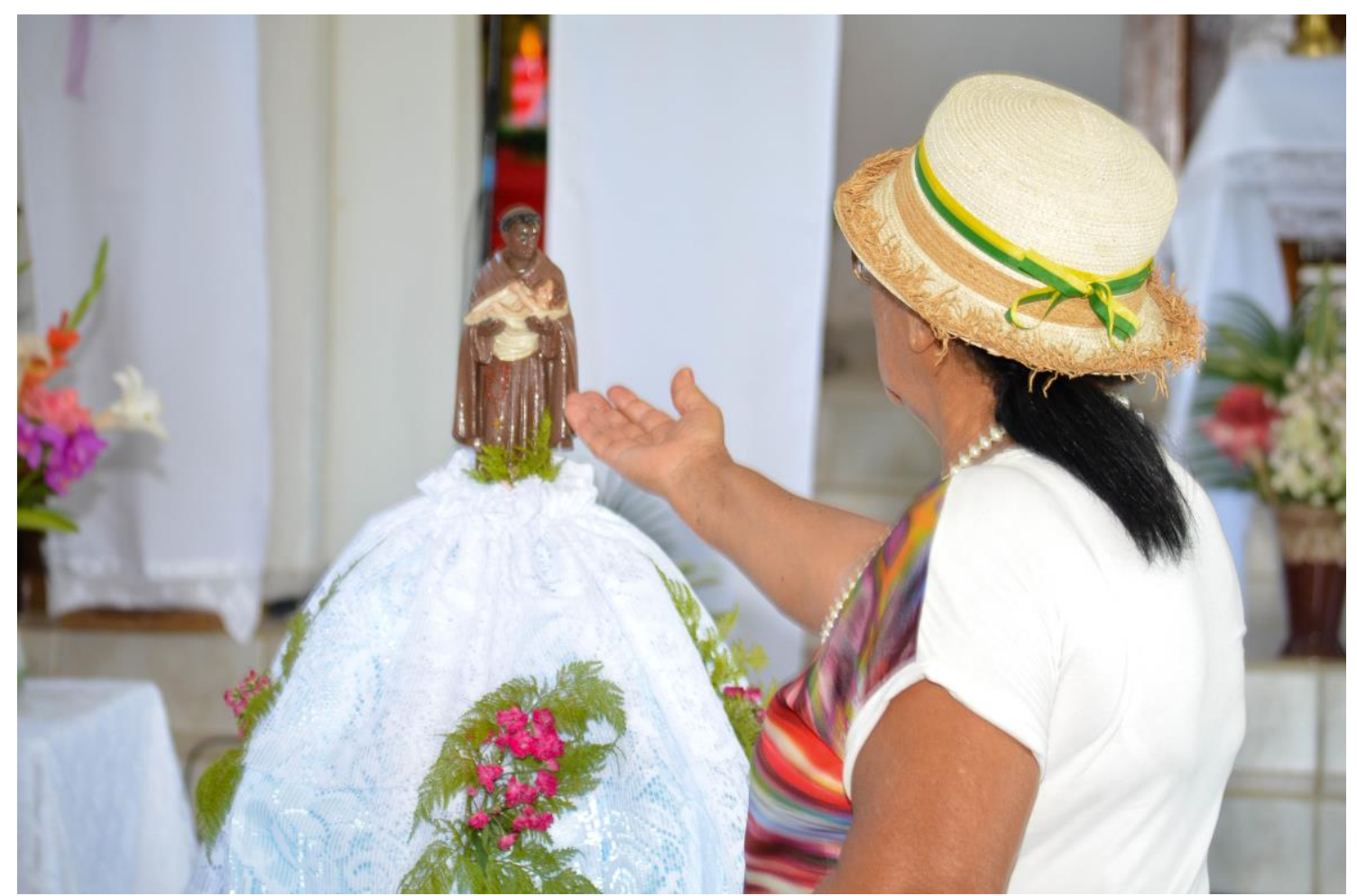

A permissão: O santo é retirado da igreja pelas mulheres após venerações e solicitação de permissão para ser conduzido por elas pela comunidade. Foto: Cristiano das Neves Bodart.

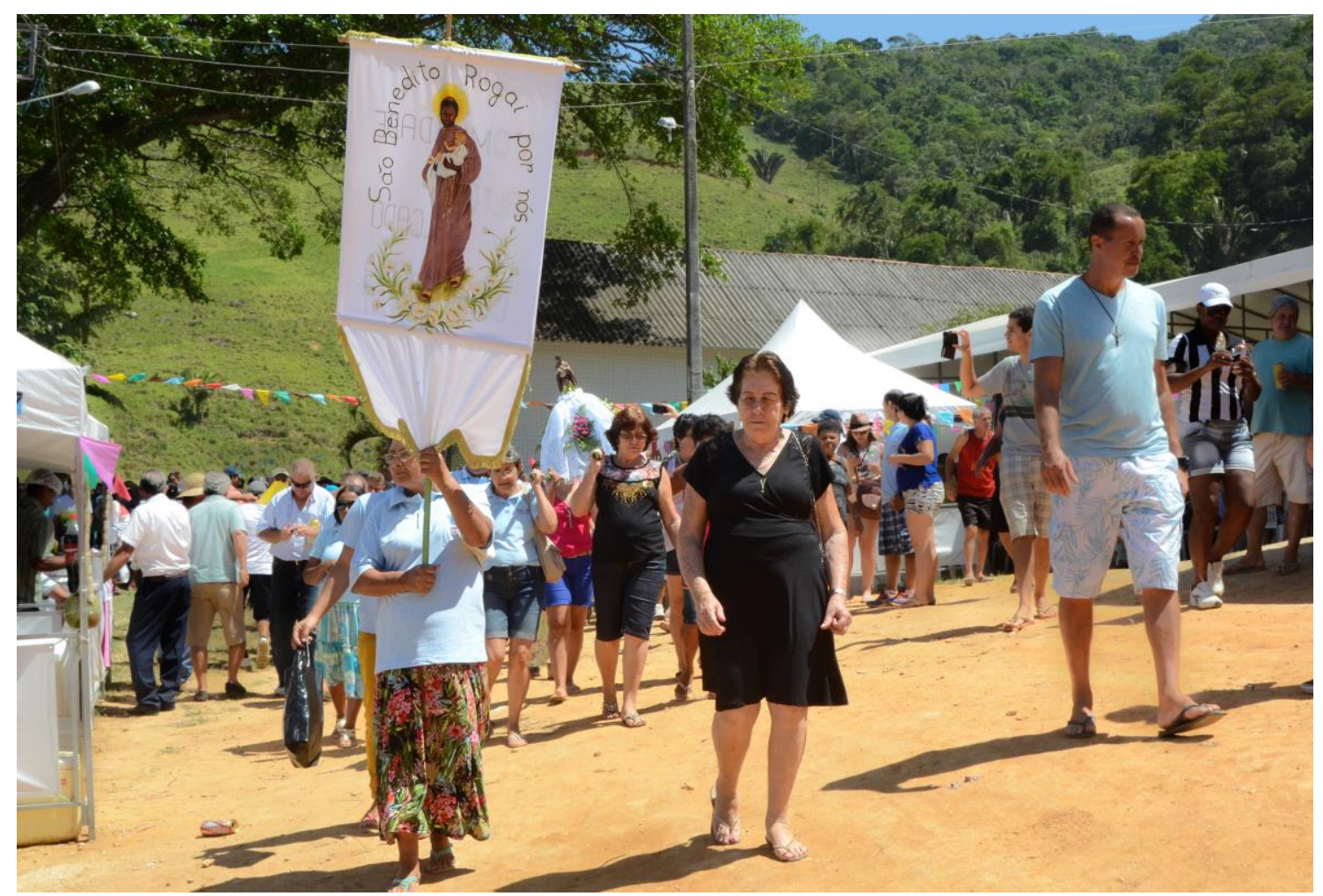

A imagem do santo é retirada do altar da igreja e conduzida em um andor, levado sobre os ombros das mulheres, as quais se deslocam até o Mastro de São Benedito localizado ao pé do morro da igreja. Nessa procissão, leva-se também, na horizontal, a bandeira para o mastro que saúda o santo e que traz o nome da comunidade, estando ela repleta de flores. Foto: Rochele Tenório da Silva. 


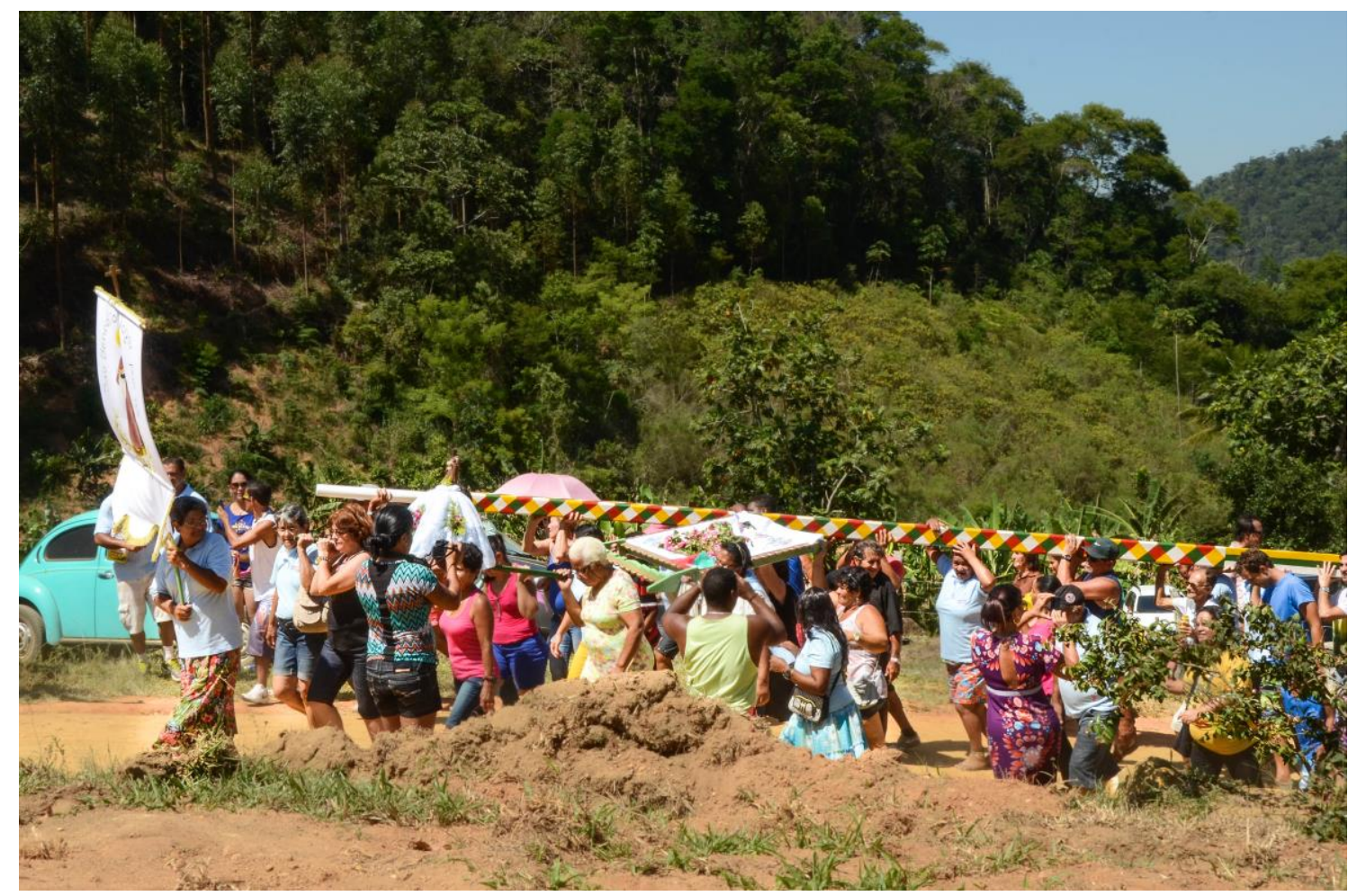

"Puxada do Mastro de São Benedito": momento de destaque e esperado pelos religiosos. Trata-se da busca do mastro, o qual será "lavado" com vinho tinto em gratidão às graças obtidas ou como rito de novas preces para o próximo ano. Foto: Rochele Tenório da Silva.

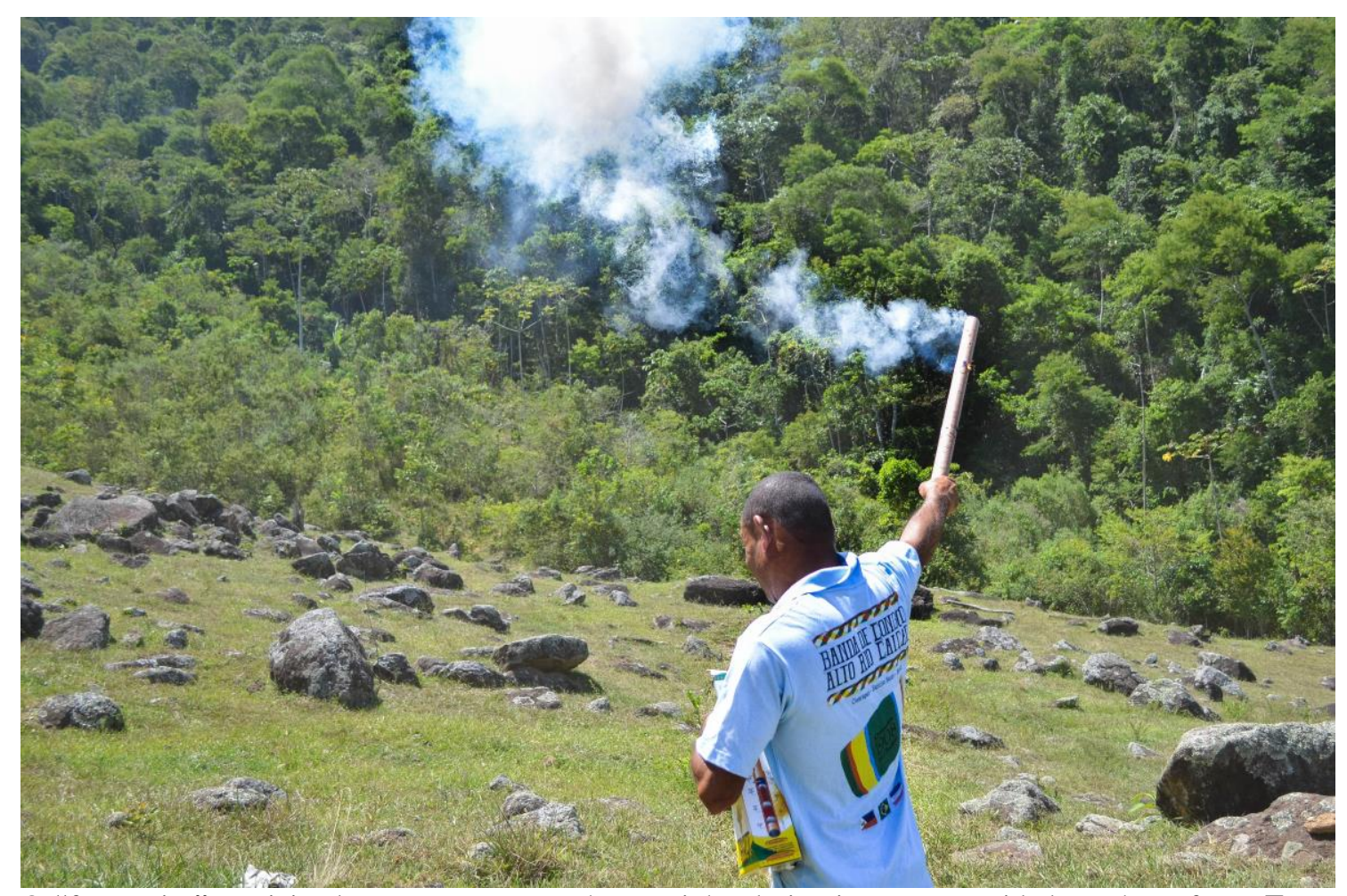

O "fogueteiro": noticiando que o mastro está a caminho da igreja e a comunidade está em festa. Foto: Cristiano das Neves Bodart. 


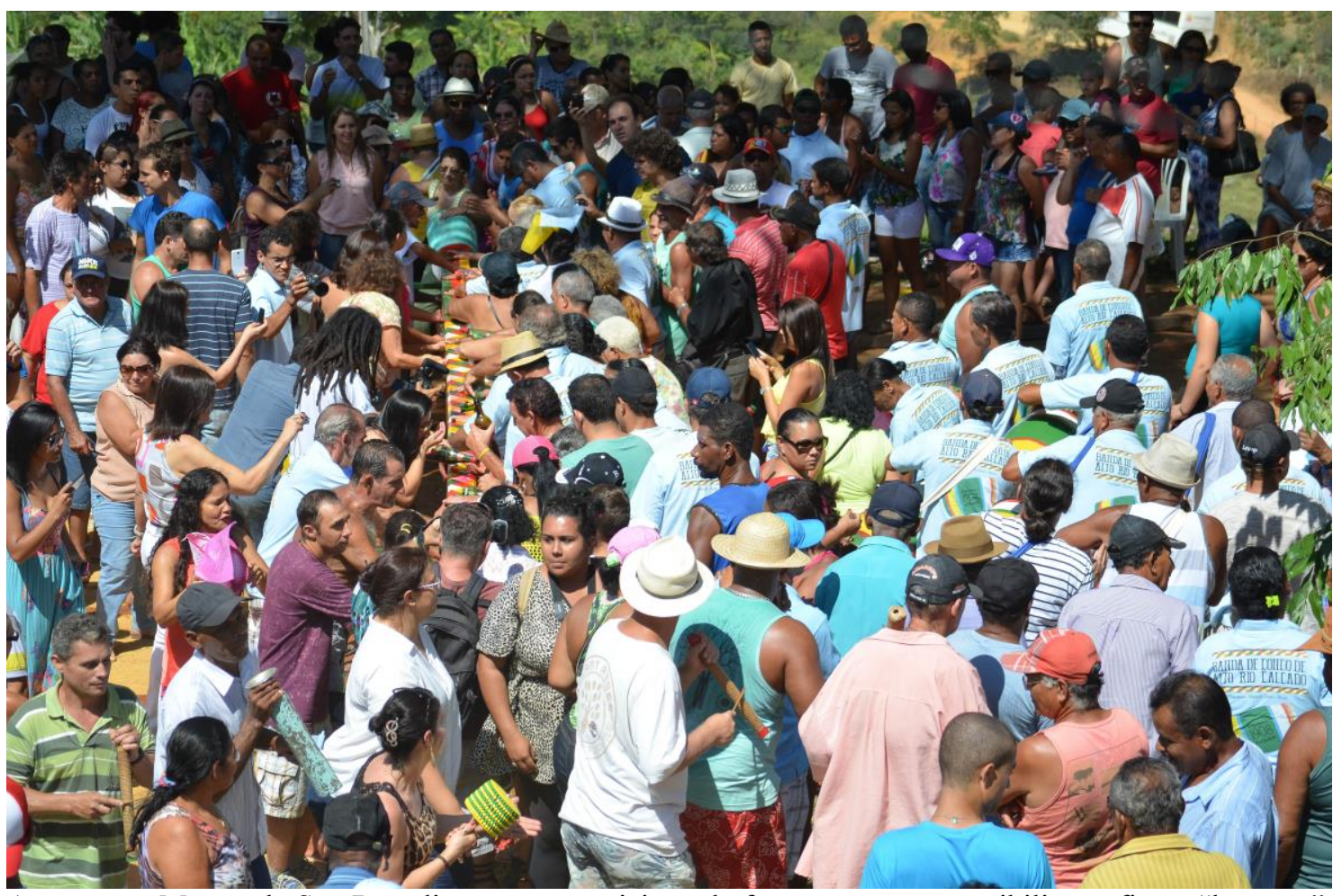

Ao trazer o Mastro de São Benedito, este se posiciona de forma com que possibilite os fies o "lavarem". Enquanto o mastro é "lavado", continua o congado, dando voltas ao redor do Mastro de São Benedito. Foto: Cristiano das Neves Bodart.

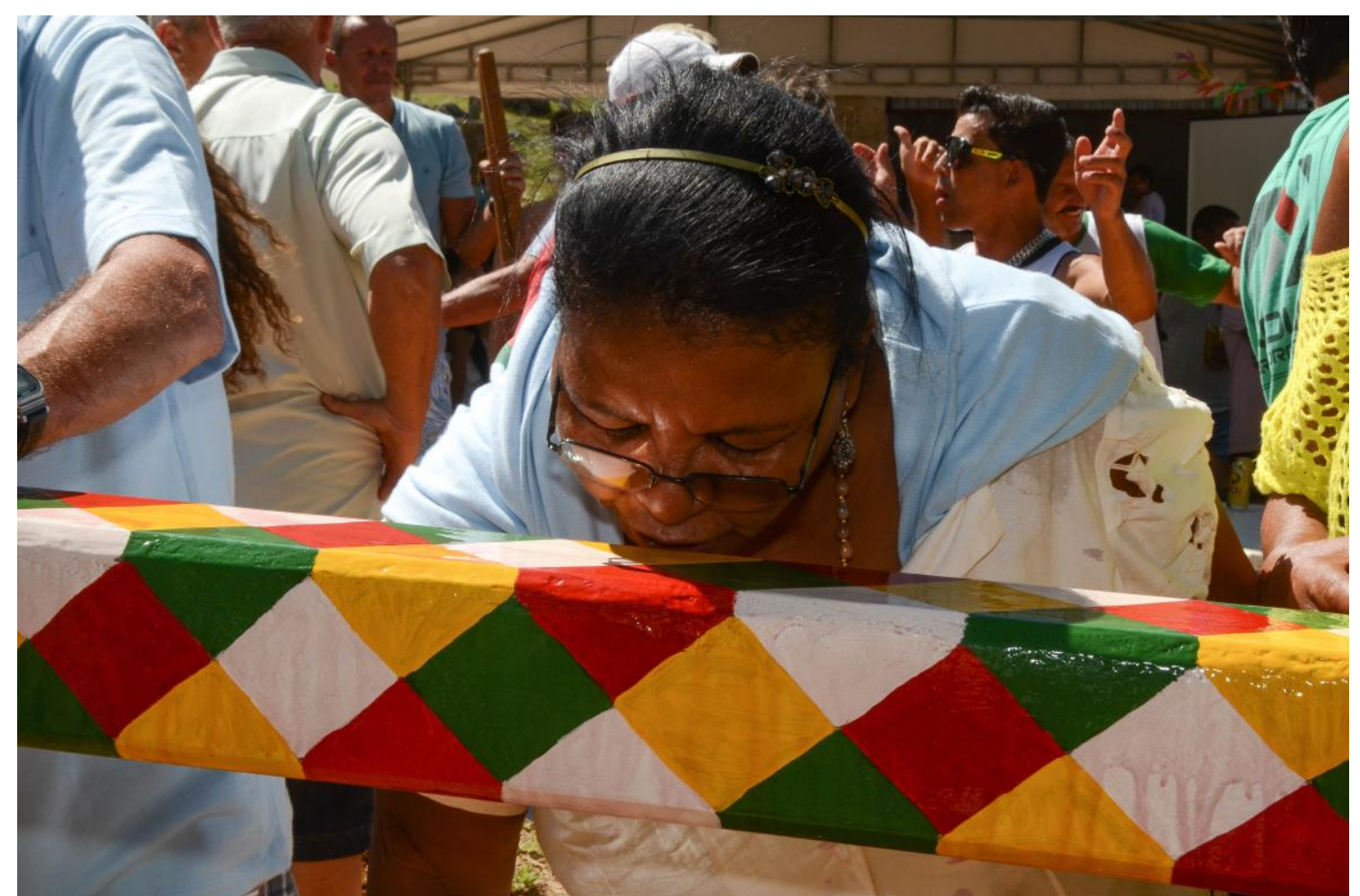

"Lavagem do Mastro de São Benedito" com vinho: Momento de agradecer as dádivas e realizar novos pedidos ao santo. As mulheres, sobretudo as mais velhas, têm prioridade na inicialização desse ato. Foto: Rochele Tenório da Silva.

Iluminuras, Porto Alegre, v. 17, n. 41, p. 329-339, jan/jun, 2016. 


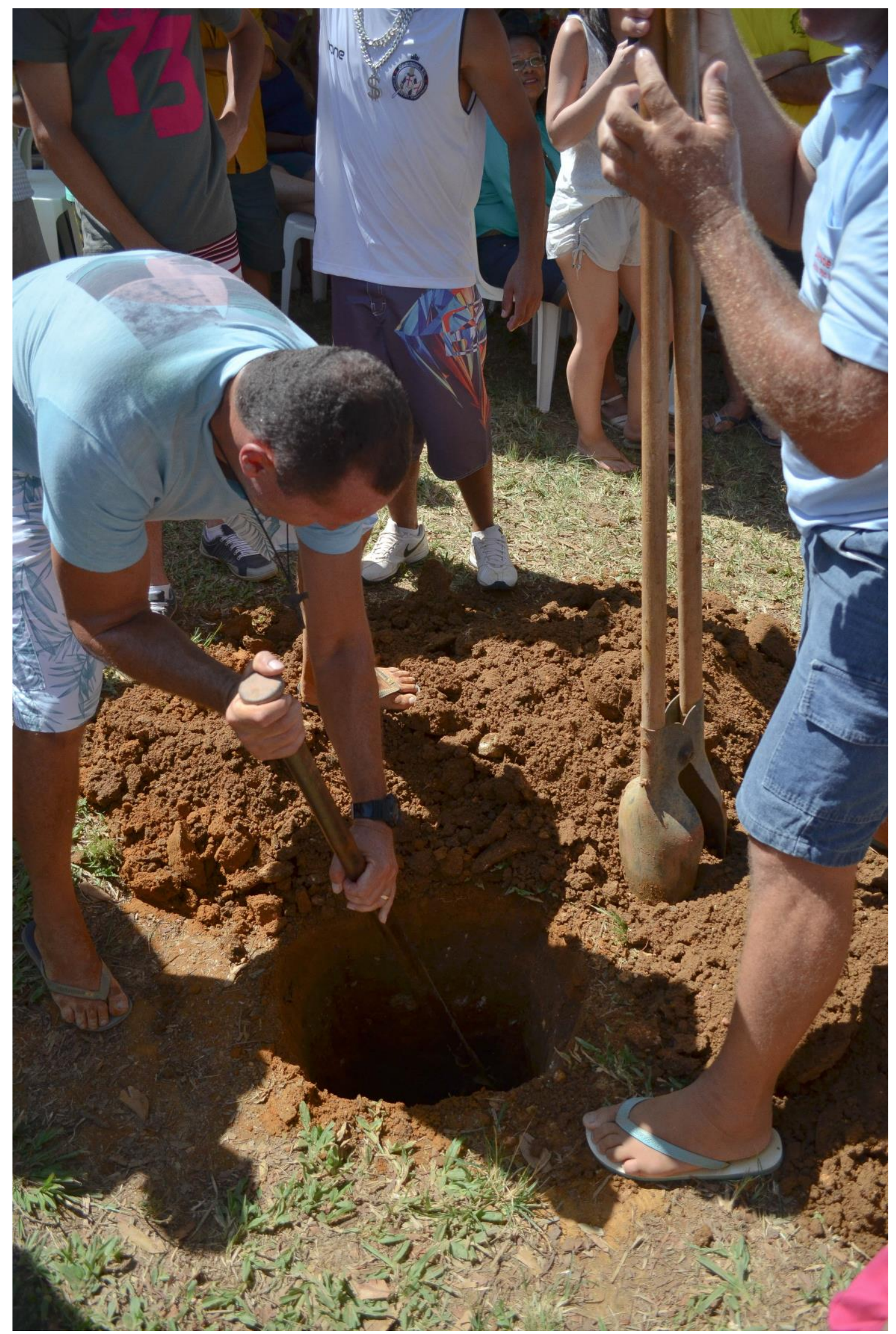

Enquanto o mastro é lavado, um grupo prepara o local para a "Enfincada do Mastro de São Benedito", sempre ao lado da Igreja. Foto: Rochele Tenório da Silva. 


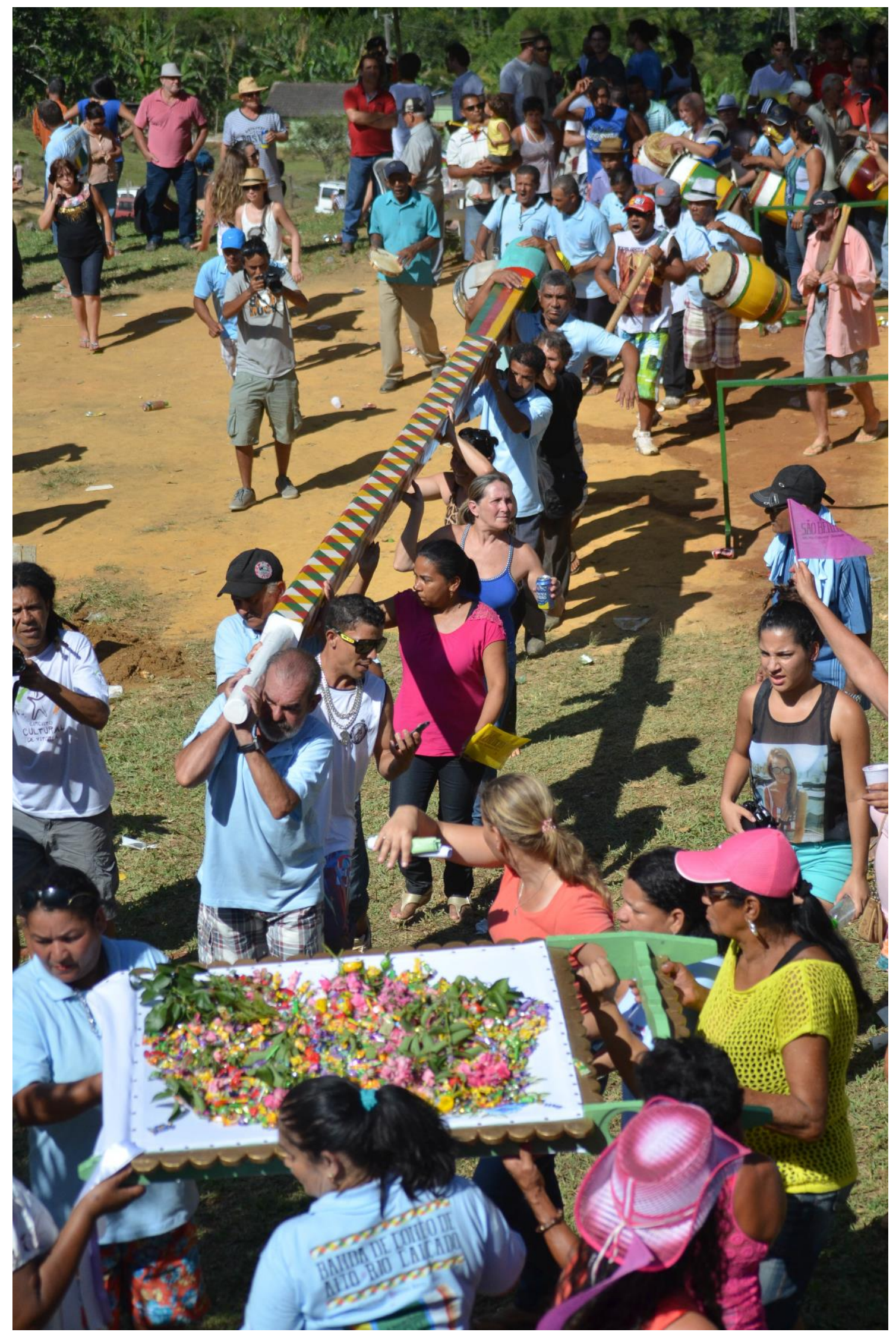

Pouco antes da "Fincada do Mastro de São Benedito", a bandeira que se encontra em posição horizontal, carregada pelas mulheres, recebe as "balas de São Benedito", as quais "entornarão" no momento em que a bandeira for encaixada no mastro e erguida. No cair das balas, os religiosos as disputam entre si. Tais balas são tidas como abençoadas pelo santo. Foto: Cristiano das Neves Bodart.

Iluminuras, Porto Alegre, v. 17, n. 41, p. 329-339, jan/jun, 2016. 


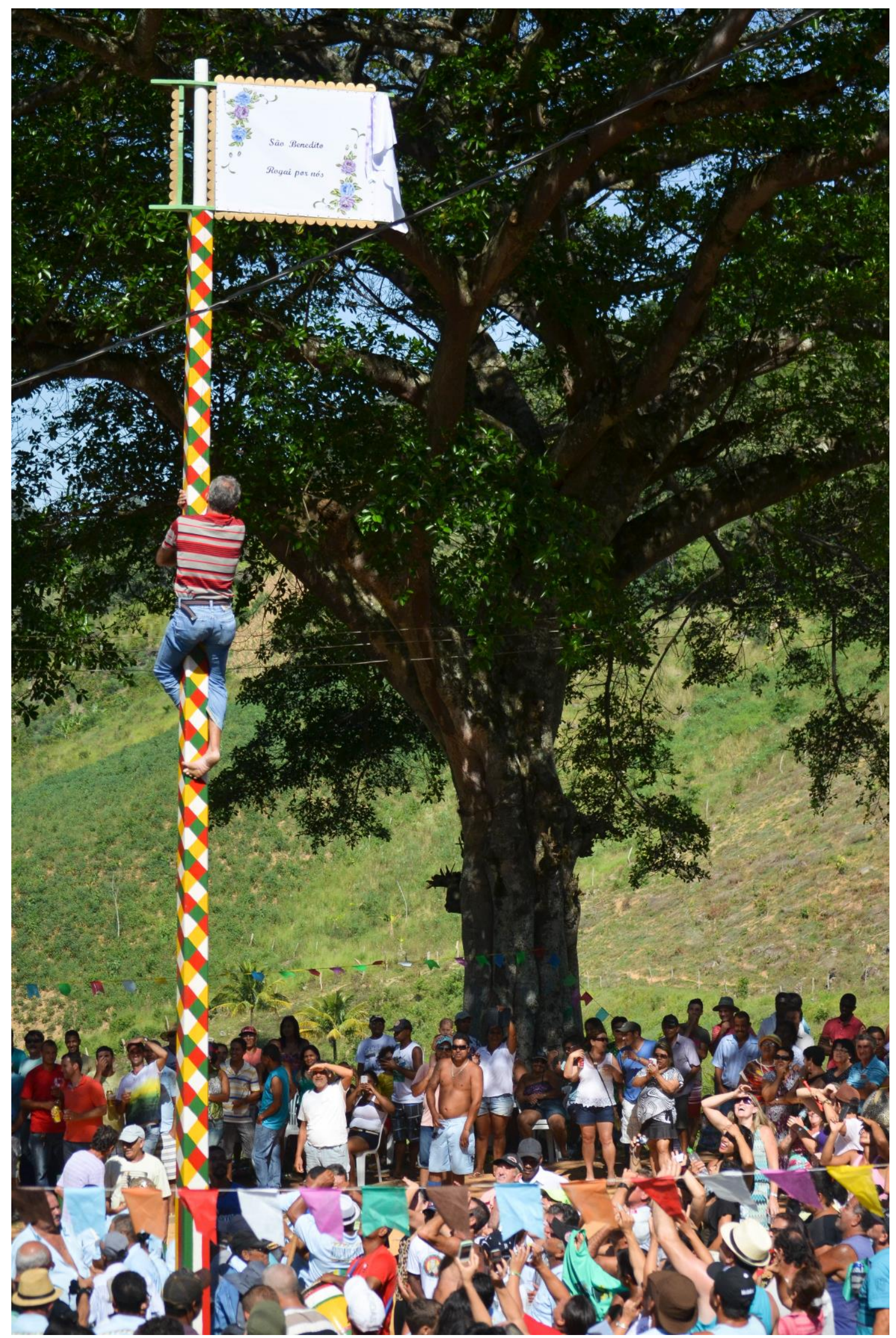

Com a fincada do Mastro de São Benedito, os homens tentam subir nesse mastro a fim de apanhar a "medalhinha de São Benedito" que fica no topo do mastro, presa na bandeira. Ao alcançar a bandeira e a medalhinha, o fiel deve girar a bandeira do mastro como prova de ter atingido o objetivo. Foto: Cristiano das Neves Bodart.

Iluminuras, Porto Alegre, v. 17, n. 41, p. 329-339, jan/jun, 2016. 


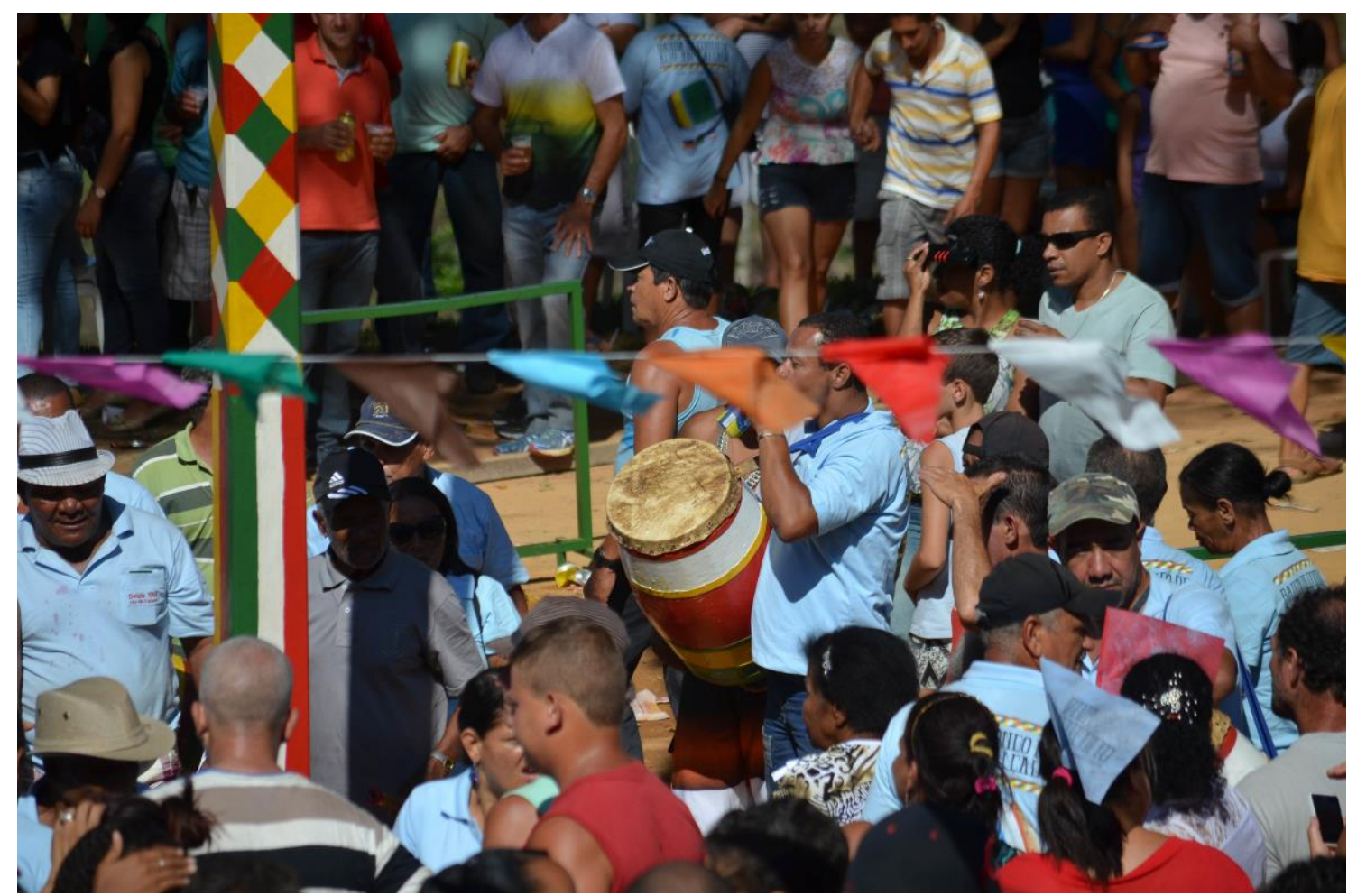

Após o ápice da cerimónia, que é a "Fincada do Mastro de São Benedito", dar-se início ao "Canto de Reis", encerrando assim o rito do dia, o qual terá continuidade dias depois com a "Retirada do Mastro". Foto: Cristiano das Neves Bodart.

\section{Referências}

ACHUTTI, Luiz Eduardo Robinson. 2004. "Fotos e Palavras, do Campo aos Livros". In: Portal da Fotoetnografia do Grupo de Pesquisa Fotografia e Fotoetnografia: Arte e Antropologia. Disponível em: $<$ http://www6.ufrgs.br/fotoetnografia/ textos/texto_achutti.pdf $>$. Acesso em: 24 jan. 2015.

ANDRADE, Rosane de. Fotografia e Antropologia: Olhares Fora-Dentro. São Paulo: Estação Liberdade, 2002.

BERGER, Jonh. Modos de ver. Barcelona: Gustavo Gili, 2007.

LEAL, Ondina Fachel. 2013. "Paisagem etnográfica: imagens, inscrições e memória nos cadernos de campo". Iluminuras, Porto Alegre, 14 (34): 62-84. Disponível em: <http://seer.ufrgs.br/index.php/iluminuras/article/viewFile/44381/28037>. Acesso em 23 jan. 2015.

Recebido em: 12/11/2015. Aprovado em: 06/04/2016. 